\title{
The effect of verbal mediation on the reduction of error to the Poggendorff illusion*
}

\author{
TERRY W. MALLENBY \\ Simon Fraser University, Burnaby, British Columbia, Canada
}

\begin{abstract}
Three groups were examined on the Poggendorff Illusion. An experiment group permitted to discuss their responses were found to show significantly less of a perceptual distortion than were two other groups not afforded this opportunity. Results were discussed in relation to perceptual developmental models.
\end{abstract}

The Poggendorff Illusion is produced by interrupting two portions of a straight oblique line by two vertical parallel lines, as shown in Fig. 1a.

Judd (1902) initially demonstrated that an illusion disappears with practice, as a result of perceptual development (i.e., maturation) rather than as a result of a judgmental process (i.e., practice). Investigation of the Poggendorff, however, has only confirmed this fact with adult Os (Pressey \& Sweeney, 1969), and not with children (Pressey \& Sweeney, 1970).

Recently, Bayer (1972) has suggested that the developmental theory of Werner (Wapner \& Werner, 1957; Werner, 1961; Werner \& Kaplan, 1967) offers a suitable perceptual explanation and model for this contradiction. Specifically, children are developmentally too immature to recognize or appreciate that the Poggendorff phenomenon is actually an illusion. Hence, practice effects do not reduce the number of errors on the illusion, as does occur with adults.

Bayer believes that, in terms of information process, children are at a lower developmental level than adults. Their perceptions are, therefore, more global, resulting in "rigid perceptual activity." Accordingly, once children are given the Poggendorff (or any illusory) task, and respond, that is what they perceive thereafter and no amount of practice should cause them to reduce their initial error. Adults, on the other hand, are seen to be more developmentally advanced; the efficacy of their information processing, subsequently, is assumed to be greater, producing more flexible perceptual activity and, therefore, greater improvement with practice.

Though both Judd (1902) and Bayer (1972) have cited perceptual models in explanation for the reduction of the illusory effects of two different illusions (i.e., Mueller-Lyer and Poggendorff, respectively), no one has yet tried to demonstrate what forms of behavioral mediation might facilitiate this perceptual process. Langer (1962) and Miller (1959), former students of Werner's, have suggested that as hierarchically integrated levels of perceptual development are attained, verbal

*This paper is sponsored by Allen Paivio who takes full editorial responsibility for it. Reprint requests: 931 Hector Ave., Winnipeg, Manitoda, Canada. mediation plays an increasingly active role in the abstract analysis of information, permitting the flexible responses typical of adults.

The present study, consequently, was designed to examine the effect of verbal mediation on the reduction of error to the Poggendorff Illusion. Verbalization was in the form of logical discussion between Os in a dyadic situation.

\section{METHOD}

\section{Subjects}

Sixty children from two grade six classes at a normal public school served as Os. There was an equal number of boys, divided into three groups, and who ranged in age from 11 year 1 month to 14 year 5 month, the mean being 12 year 1 month. None of the Os wore glasses.

\section{Apparatus}

Two 8 by $11 \mathrm{in}$. stimulus cards were employed. One illustrated the Poggendorff Illusion (Po stimulus card), shown in Fig. 1b. The dimensions of the illusion were identical to that
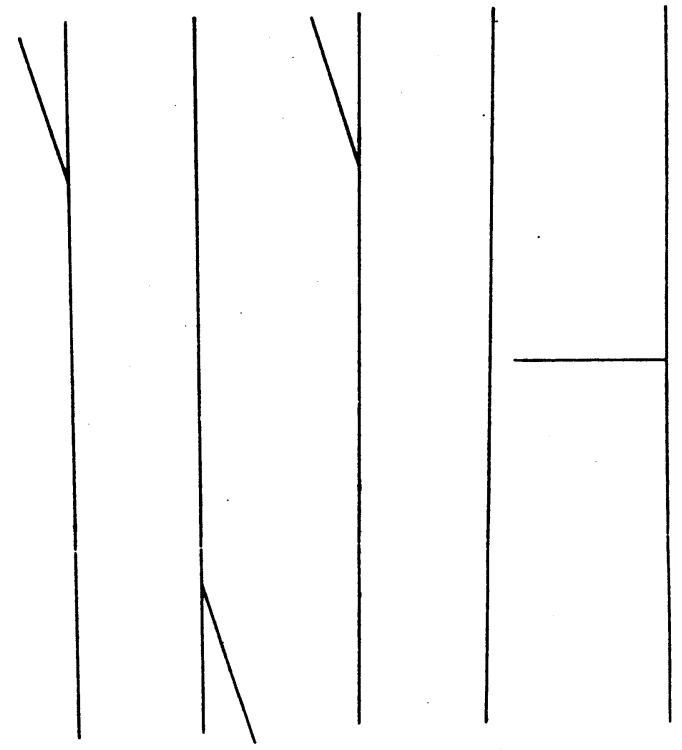

$$
\mid
$$

Fig. 1: (a) Poggendorff Illusion; (b) Po Stimulus Card; (c) Pr stimulus Card. 
used by Pressey and Sweeney (1969). It consisted of two 7-in. parallel vertical lines, 1.125 in. apart. A 1.5 -in. diagonal line joined the vertical line on the left at a distance of $1.5 \mathrm{in}$. from the top of the line. The angle formed by the diagonal and vertical lines was $20 \mathrm{deg}$.

The second stimulus card was a practice card (Pr stimulus card) for the Poggendorff Illusion, which appears in Fig. 1c. It had identical dimensions to that of the Po stimulus card, except that the oblique line in the Pr card was now perpendicular to the left vertical line, and joined that line at a distance of 3.5 in. from the top.

\section{Procedure}

The Os were initially divided into three groups of 20 boys each. Os from Group 1 were examined one at a time, while those from Groups 2 and 3 were tested in pairs. The experimental room consisted of a private office (approximately $12 \times 12 \mathrm{ft}$ ) in the school. ${ }^{1}$ There was one desk, and a suitable number of chairs for $\mathrm{E}$ and Os. Tile Os sat to E's right. Illumination was supplied by normal fluorescent lighting plus a large window directly behind $\mathrm{E}$ and $\mathrm{Os.}$

The stimuli were not presented in a confining apparatus, as was used by Pressey, Bayer, and Kelm (1969), but were rather presented in an unrestricted situation. The stimulus cards, which were initially hidden from view, were presented directly to the O's visual field face-up on the desk. For each of the six presentations of identical Po stimulus cards, the Os were required to mark a fine, but well defined, dot on the right vertical line at the pont where the oblique line would join, if it were extended. OS were required to respond after viewing eacil stimulus card for $10 \mathrm{sec}$.

All instructions were given verbally so that queries could be answered immediately. If, for example, any of the Os did not understand the task, tile $\mathrm{E}$ would simplify the instructions by saying, "See this little line (while pointing to the perpendicular line on the Pr stimulus card)? Where would it cross this longer line on the right (while pointing to the right vertical line), if it were extended?" Befo ie th: Po stimulus cards were exhibited, the E demonstrated the task with a Pr card. The Os were also required to respond to one Pr card to make sure they understood the task.

Specific instructions for each group were as follows: For experimental Group 1, where the Os were examined individually, it was further specified that they were not to touch the stimulus cards until the l: had indicated that they may make their response. In control Group 2, where the Os were examined in pairs, they were instructed not to touch the stimulus card, nor were they able to talk with their partner during the session. The I: instructed alternate $O$ s to respond after the required time limit had elapsed. For experimental Group 3, where the boys were also examined in pairs, they were instructed to describe their reasons to the other () , discuss these perceptions, and finally come to an agreement as to where the response dot was to be marked (The Os were only permitted to touch the right vertical line during these discussions so that each had a reference point while communicating to the other $\mathrm{O}$ as to where to place the dot). After the required session time had elapsed, alternate Os were asked to record their agreed upon response.

Since agreement between the Os prior to any response was the major concern for this third group, the 10-sec viewing interval was not strictly adhered to. It was noted, however, that near the end of the stimulus presentations, consensus between the Os had occurred before the compulsory interval had expired.

\section{RESULTS}

Measurements were accurate to within $0.125 \mathrm{in}$. The mean error size to the illusion for each group over successive trials (i.e., practice effects) appears in Table 1.
Table 1

Mean Size of the Illusion for Each Group Over Successive Trials

\begin{tabular}{|c|c|c|c|c|c|c|}
\hline \multirow[b]{2}{*}{ Group } & \multicolumn{6}{|c|}{ Successive Trials } \\
\hline & 1 & 2 & 3 & 4 & 5 & 6 \\
\hline 1 & 15.0 & 13.5 & 12.5 & 13.5 & 13.5 & 12.5 \\
\hline 2 & 12.5 & 11.5 & 12.2 & 12.5 & 11.3 & 11.5 \\
\hline 3 & 7.0 & 5.9 & 6.9 & 6.6 & 6.6 & 5.2 \\
\hline
\end{tabular}

Note-The illusion is reported in .125-in. units. The mean SD for Group $1=.72$, Group $2=.40$, Group $3=.21$. Group 1 was examined individually. Group 2 was examined in pairs, but was not permitted to discuss responses. Group 3 was examined in pairs, but was permitted to discuss responses.

It is clear that Groups 1 (experimental group) and 2 (control group for Group 3) which were unable to verbalize their responses, perceived a greater degree of distortion to the illusion than had experimental Group 3, which had been able to verbalize responses (F $=8.22 ; \mathrm{df}=2 / 47 ; \mathrm{p}<.01$ ). The effect of practice (i.e., successive trials) was not significant for any of the three groups.

\section{DISCUSSION}

Although perceptual theories have been reported as suitable models (Bayer, 1972) to explain the discrepancy between a child's and an adult's perceptual distortion to an illusion, the present experiment has demonstrated that children can actually perform better (i.e., less distortion) than have adults as reported in other research (Pressey \& Sweeney, 1969). Thus, although it has previously been assumed that children are unable to perceptually process illusory information as well as adults, the present results suggest that they can, under certain circumstances. Specifically, as suggested by Langer (1962) and Miller (1959), verbal mediation may play an important role in the processing of perceptual information.

Thus, it seems that perceptual development (i.e., maturation) per se (Bayer, 1972) cannot adequately explain the present abilities of child ren permitted to verbally discuss their responses between themselves. Social facilitation, although perhaps aiding in the reduction of error to the illusion, as suggested by smaller distortion effects for Group 2 than for Group 1, cannot in total account for the significant decrease in errol for Group 3.

It now becomes the task for further research to examine why children permitted to discuss their responses should perform so much better than other children not afforded this opportunity. This question is further complicated in that none of the children performed better (i.e, with less distortion) with practice (i.e., successive trials). If it is an accurate assumption that verbal mediation permits the flexible responses typical of adults, than one would expect Group 3, at least, to perform increasingly better with the amount of practice. Although Table 1 seeming tly demonstrates this trend, successive trials effects were not significant for any of the three groups. The as yet unanswered question is, why?

Since the children permitted only to view, and not to discuss, the Poggendorff Illusion exhibited distortion similar to that found in previous research (Leibowitz \& Gwozdecki, 1967), the unrestricted responding situation employed in the present study seems to be just as effective in recording perceptual responses as more restricted methods (e.g., Pressey \& Sweeney, 1970). The present procedure, in addition, permits future analysis of other important behavioral variables (like, verbal mediation, social facilitation, posture, body orientation, sensorimotor tracing, etc.) related to the perceptual process of illusions. 


\section{REFERENCES}

Bayer, C. A. An explanation of developmental differences in the successive trials effect of the Poggendorff Illusion. Psychonomic Science, 1972, 26, 85-86.

Judd, C. H. Practice and its effects on the perception of illusions. Psychological R eview, 1902, 9, 27-39.

Langer, J. The representatin of perceptual phenomena: A comparison of nonverbal (linear) representations with linguistic coding. Unpublished doctoral dissertation, Clark University, 1962.

Leibowitz, H. W., \& Gwozdecki, J. The magnitude of the Poggendorff Illusion as a function of age. Child Development, $1967,38,573-580$.

Miller, A. An experimental study of the role of sensory-motor activity in the retention of verbal meaning. Unpublished doctoral dissertation, Clark University, 1959.

Pressey A. W Bayer, C. A., \& Kelm, H. The Poggendorff in schizophrenic patients. Schizophrenia, 1969, 1, 88-94.

Pressey, A. W., \& Sweeney, O. A variation of the Poggendorff
Illusion. Perceptual \& Motor Skills, 1969, 28, 883-886.

Pressey, A. W., \& Sweeney, O. Age changes in the Poggendorff ulusion as measured by a method of production. Psychonomic Science, 1970, 19, 100.

Wapner, S. \& Werner, H. Perceptual Developmenta: An investigation within the framework of sensory-tonic field theory. Worcester: Clark University Press, 1957.

Werner, $\mathrm{H}$. Comparative psychology of mental development. New York: Science Editions, 1961.

Werner, H., \& Kaplan, B. Symbol Formation. New York: Wiley, 1967.

\section{NOTE}

1. Appreciation is extended to G. Little, principal of Victoria School in Portage La Prairie, Manitoba, for his kind cooperation and the use of the school facilities during these studies.

\title{
Attenuation of novelty preference: Homeostatic arousal or retrograde amnesia?
}

\author{
J. L. MOTTIN and R. W. GATEHOUSE \\ University of Guelph, Guelph, Ontario, Canada
}

\begin{abstract}
Wistar rats habituated to one arm (either black or white; left or right) of a Y-maze and tested for novelty preference via a free choice to enter the novel or familiar maze arm, consistently preferred the novel route except when preexposed to ECS stimulation, Contrary to a previously favored hypothesis of homeostatic arousal, exposure to intense white noise $(94-102 \mathrm{~dB} ; 15 \mathrm{sec}-4 \mathrm{~h}$ ) failed to produce choice frequencies different from the preference for novelty exhibited under nonarousing control conditions. These results lend support to an alternative interpretation based on an assumed disruption of habituation processing.
\end{abstract}

Although a relatively large body of knowledge is accumulating about the physiological and anatomical correlates of noise pollution, relatively little is known about its psychological dimensions. In one of the few studies in the latter vein, Haywood and Wachs (1967) suggested that noise stimulation may alter the organism by arousing the information processing system beyond an optimal level of stimulation and inducing a return to equilibrium. Behaviorally, an organism so aroused by noise would tend to seek the familiar in preference to novel stimulus conditions (presumably novelty would induce only further arousal). The Haywood and Wachs experiment supported this view by demonstrating a reduction of choice behavior to chance level in rats exposed to intense white noise, while unexposed rats strongly preferred the novel choice.

While the homeostatic arousal hypothesis presents a

The authors would like to thank M. R. Denny for his comments and suggestions, and for sponsoring and taking the editorial responsibility for this paper. The study was supported by Research Advisory Board, University of Guelph Grant 694-13. new dimension to the possible psychological effects of noise, there are several problems to contend with. The hypothesis predicts a clear preference for the familiar, whereas Haywood and Wachs's manipulations failed to produce choice frequencies below chance levels, leaving open the possibility that the absence of any preference under noise conditions was the result of an interruption of habituation effects, creating an absence of "novelty choice." It should be noted that Haywood and Wachs referred to this as an alternative hypothesis. But no investigation of this alternative explanation has occurred, although Sheldon (1968) acknowledged the possible role of disruption in the effects of shock on novelty preference.

Moreover, the physical properties of the white noise stimulation remain undocumented, reference having been made only to psychological adjustments to levels "just less than that required to produce audiogenic seizures" (Haywood \& Wachs, 1967, Pp. 78). Precise replication of the noise manipulations thus remains extremely difficult given that the literature and pilot studies in our laboratory have failed to reveal threshold 